\title{
Mitogen-Activated Protein Kinase Signaling in the Hippocampus and Its Modulation by Corticotropin- Releasing Factor Receptor 2: A Possible Link between Stress and Fear Memory
}

\author{
Farahnaz Sananbenesi, André Fischer, Christina Schrick, Joachim Spiess, and Jelena Radulovic \\ Laboratory on Cell Biologic Mechanisms of Memory, Department of Molecular Neuroendocrinology, Max Planck Institute for Experimental Medicine, \\ 37075 Goettingen, Germany
}

A coordinated activation of multiple interlinked signaling pathways involving cAMP-dependent protein kinase (PKA) and mitogenactivated extracellular signal-regulated kinases (Mek-1/2) regulates gene expression and neuronal changes underlying memory consolidation. In the present study we investigated whether these molecular cascades might mediate the effects of stress on memory formation. We also investigated the role of hippocampal corticotropin-releasing factor receptor $2\left(\mathrm{CRF}_{2}\right)$ in stress-enhanced learning and molecular signaling mediated by PKA, Mek-1/2, and their downstream targets extracellularly regulated kinases 1 and 2 (Erk-1/2) and p90ribosomal-s-kinase-1 (p90Rsk-1).

Acute $1 \mathrm{hr}$ immobilization was used as a stressful stimulus, and one-trial context-dependent fear conditioning was used as a model for associative learning. Training of BALB/c mice $3 \mathrm{hr}$ after the end of immobilization resulted in an enhancement of conditioned fear, as indicated by significantly increased freezing behavior of stressed when compared with nonstressed mice. Interestingly, Erk-1/2 phosphorylation after conditioning of nonstressed and stressed mice depended on PKA and Mek-1/2, respectively. Intrahippocampal injection of the selective Mek-1/2 inhibitor U0126 or $\mathrm{CRF}_{2}$ antagonist antisauvagine-30 (aSvg-30) prevented stress-enhanced fear conditioning and Mek-1/2-dependent activation of Erk-1/2 and p90Rsk-1. aSvg-30 did not affect the phosphorylation of the PKA regulatory subunit II of stressed mice. The molecular and behavioral effects of $\mathrm{CRF}_{2}$ coincided with stress-induced upregulation of $\mathrm{CRF}_{2} \mathrm{mRNA}$.

These results suggest that modulation of Mek-1/2-dependent signaling by hippocampal $\mathrm{CRF}_{2}$ can be selectively involved in the delayed effects of stress on memory consolidation.

Key words: stress; fear conditioning; MAPK; PKA; Erk; CRF receptor 2; hippocampus

\section{Introduction}

Formation of long-term memory requires a series of molecular processes involving the activation of intracellular signaling cascades and gene expression leading to persistent synaptic alterations. Extracellular signal-regulated kinases (Erks) belong to the family of mitogen-activated protein kinases (MAPKs) that integrate signals received by membrane receptors and transfer them to the nucleus (Cano and Mahadevan, 1995). The phosphorylation state and activity of Erk isoforms 1 and 2 (Erk-1/2) may be modified by mitogen-activated extracellular signal-regulated kinases (Mek-1/2) and cAMP-dependent protein kinase (PKA) (Impey et al., 1998; Roberson et al., 1999). Subsequent coupling of cytoplasmic signaling to gene expression occurs through Erk-

\footnotetext{
Received July 21, 2003; revised Sept. 22, 2003; accepted 0ct. 22, 2003.

This work was supported by the Max Planck Society. We thank L. van Werven for synthesis for antisauvagine-30 and T. Liepold for amino acid analyses.

Correspondence should be addressed to Farahnaz Sananbenesi, Laboratory on Cell Biologic Mechanisms of Memory, Max Planck Institute for Experimental Medicine, Hermann-Rein-Strasse 3, 37075 Goettingen, Germany. E-mail: sananbenesi@mail.em.mpg.de.

Copyright $\odot 2003$ Society for Neuroscience $\quad$ 0270-6474/03/2311436-08\$15.00/0
}

1/2-mediated serine-threonine phosphorylation of their downstream targets, such as ribosomal S6 kinases 1-3 (p90Rsk-1-3), acting as transcription regulators (Chen et al., 1992). It is assumed that PKA and Mek-1/2 belong to the core signaling pathways involved in memory storage (for review, see Kandel, 2001; Matynia et al., 2001; Sweatt, 2001).

Memory can be markedly enhanced by acute stressful experiences (Shors et al., 1992; Radulovic et al., 1999; Roozendaal et al., 2002), even when training is performed after cessation of the stress response. Although stress can clearly modulate memory formation, the neuronal substrates through which this is accomplished are not fully elucidated. One candidate is corticotropinreleasing factor (CRF), a neuropeptide rapidly released in response to stressors (Spiess et al., 1981; Vale et al., 1981). CRF and its related peptide urocortin (Vaughan et al., 1995) exert their biological actions via two receptors, $\mathrm{CRF}_{1}$ and $\mathrm{CRF}_{2}$ (for review, see Eckart et al., 2002). Other peptides of the same family, such as urocortin II (Hsu and Hsueh, 2001; Reyes et al., 2001) and urocortin III (Lewis et al., 2001), bind selectively to $\mathrm{CRF}_{2}$.

Under certain conditions, CRF can improve learning without significantly affecting arousal, motivational, or anxiety-like be- 
havior (Behan et al., 1995; Radulovic et al., 1999). CRF-mediated enhancement of hippocampus-dependent learning (Zorrilla et al., 2002) and excitability (Blank et al., 2003) depends on $\mathrm{CRF}_{1}$. Both $\mathrm{CRF}_{1}$ and $\mathrm{CRF}_{2}$ mRNA have been detected in the hippocampus (Van Pett et al., 2000); however, a possible role of hippocampal $\mathrm{CRF}_{2}$ in learning and memory has not yet been identified.

$\mathrm{CRF}_{1}$ and $\mathrm{CRF}_{2}$ are $\mathrm{G}$-protein-coupled receptors that activate adenylate cyclase leading to increased intracellular cAMP concentrations (De Souza, 1995). Studies with cell lines indicate that CRF activates both the PKA and Mek-1/2 signaling pathways (Elliott-Hunt et al., 2002) by acting through $\mathrm{CRF}_{1}$ (Pedersen et al., 2002; Radulovic et al., 2003) or $\mathrm{CRF}_{2}$ (Rossant et al., 1999). Thus, CRF receptors might also modulate Erk-1/2 signaling in vivo.

The objective of this study was to delineate the involvement of PKA and Mek-1/2 in Erk-1/2 signaling during fear conditioning (FC) and stress-enhanced fear conditioning (stress/FC) and investigate the role of $\mathrm{CRF}_{2}$ in the modulation of these processes. On the basis of the demonstrated involvement of Erk-1/2, activated by PKA (Sananbenesi et al., 2002) or Mek-1/2 (Atkins et al., 1998; Schafe et al., 2000; Athos et al., 2002), in associative learning, we assumed that delayed alterations of these cascades could be crucial for consolidation of stress-modulated memories.

\section{Materials and Methods}

Animals. Nine-week-old male BALB/c mice (Charles River, Sultzfeld, Germany) were housed individually as described (Radulovic et al., 1999). Experiments were performed in accordance with the European Council Directive (86/609/EEC) with the permission of the Animal Protection Law enforced by the District Government of Braunschweig, Germany. The number of mice per group was $4-5$ for protein production studies and $8-12$ for behavioral experiments.

Cannulation and injections. Cannulation into the dorsal hippocampus was performed as described (Fischer et al., 2002). Briefly, mice were anesthetized with an intraperitoneal injection of $1.2 \%$ Avertin (2,2,2-tribromethanol dissolved in $0.7 \%$ isoamyl alcohol; $0.4 \mathrm{ml}$ per mouse). Double-guided cannulas (internal, 28 gauge; guide, 26 gauge) were inserted bilaterally into the dorsal hippocampi (intrahippocampal injection; $1.5 \mathrm{~mm}$ posterior to the bregma, $1 \mathrm{~mm}$ lateral to the sagittal suture, $2 \mathrm{~mm}$ in depth relative to the skull). Mice were allowed to recover for $5 \mathrm{~d}$. Injections were performed under light isofluran anesthesia (Coramed Pharma GmbH, Karlsruhe, Germany) over a $30 \mathrm{sec}$ period ( $0.25 \mu \mathrm{l}$ per site) by a microinjector system (CMA/Microdyalsis, Solna, Sweden). The $\mathrm{CRF}_{2}$ antagonist antisauvagine-30 (aSvg-30) (400 ng/0.5 $\mu \mathrm{l}$ per mouse), Mek inhibitor U0126 ( $1 \mu \mathrm{g} / 0.5 \mu \mathrm{l}$ per mouse), and PKA inhibitor adenosine 3',5'-cyclic monophosphorothioate, Rp-isomer, triethyammonium salt (Rp-cAMPS) $(18 \mu \mathrm{g} / 0.5 \mu \mathrm{l}$ per mouse) were injected $15 \mathrm{~min}$ before training or immobilization as indicated. Vehicle was 50\% DMSO in artificial CSF (aCSF) containing (in $\mathrm{mm}$ ): $130 \mathrm{NaCl}, 3 \mathrm{KCl}, 1.25$ $\mathrm{NaH}_{2} \mathrm{PO} 4,26 \mathrm{NaHCO} 3,1 \mathrm{MgCl}_{2}, 10$ glucose, $2 \mathrm{CaCl}_{2}$ for U0126, $5 \mathrm{~mm}$ acetic acid in aCSF for antisauvagine- 30 or aCSF for Rp-cAMPS. The doses of the antagonists were selected on the basis of pilot experiments as well as previous studies demonstrating that the used doses of aSvg-30 (Radulovic et al., 1999), U0126 (Schafe et al., 2000), and Rp-cAMPS (Sananbenesi et al., 2002) effectively prevented fear conditioning. After the end of animal treatments, aliquots of antisauvagine- 30 solutions were subjected to amino acid analysis. Injections of methylene blue were performed at the end of the experiments for each mouse to verify the cannula position. Photomicrographs showing typical histological analysis of cannulas correctly inserted into the dorsolateral hippocampus were shown in detail in our recent study (Fischer et al., 2003). Only mice with correctly inserted cannulas were used for statistical analyses.

Immobilization stress. Immobilization of mice consisted of taping their limbs to a Plexiglas surface for $1 \mathrm{hr}$ (Smith et al., 1995; Radulovic et al., 1999). Control mice were left in their home cages and exposed to the same context without immobilization.
Context-dependent fear conditioning. Training consisted of a $3 \mathrm{~min}$ exposure of mice to the conditioning box (context) followed by a foot shock (2 sec, $0.7 \mathrm{~mA}$, constant current) (Radulovic et al., 1998). The memory test was performed $24 \mathrm{hr}$ later by re-exposing the mice for $3 \mathrm{~min}$ to the conditioning context. Freezing, defined as a lack of movement besides heart rate and respiration associated with a crouching posture, was recorded every $10 \mathrm{sec}$ for $1 \mathrm{sec}$ by two trained observers (one was unaware of the experimental conditions) during a period of $3 \mathrm{~min}$ (a total of 18 sampling intervals). The number of scores indicating freezing was calculated as a mean from both observers and expressed as a percentage of the total number of observations. We have demonstrated previously that freezing observed after the used fear-conditioning procedure specifically reflects associative learning by absence of freezing after exposure to an immediate foot shock ( $2 \mathrm{sec}, 0.7 \mathrm{~mA}$, constant current) followed by context (3 min) (Milanovic et al., 1998; Stanciu et al., 2000; Sananbenesi et al., 2002). We also showed that the conditioning procedure, stress, and CRF treatments selectively affected freezing in the conditioning but not in a novel context (Radulovic et al., 1999). Mice of the naive control group were handled and treated the same as the experimental groups except that stress and conditioning were omitted.

Chemicals and antibodies. The PKA inhibitor Rp-cAMPS was purchased from Calbiochem (La Jolla, CA). The Mek Inhibitor U0126 was from Promega (Madison, WI). Antisauvagine-30 was synthesized with the Fmoc strategy on solid phase (Ruhmann et al., 1998). Immunoblot analyses were performed using antibodies specific for Mek1/2 (rabbit polyclonal IgG, 12-B; Santa Cruz Biotechnology, Santa Cruz, CA), Mek1/2 phosphorylated at Ser-217/221 (pMek-1/2; rabbit polyclonal IgG; Cell Signaling), Erk-1/2 (rabbit polyclonal IgG, K-23; Santa Cruz Biotechnology), Erk-1/2 phosphorylated at Thr-183/Tyr-185 (pErk-1/2; mouse monoclonal IgG; Sigma, St. Louis, MO), p90Rsk-1 (rabbit polyclonal IgG, C-21; Santa Cruz Biotechnology), p90Rsk-1 phosphorylated at Thr-360/Ser-364 (pp90Rsk-1; rabbit polyclonal IgG; Sigma), PKA RII phosphorylated at Ser-96 (pPKA; Upstate Biotechnology, Lake Placid, NY), and actin (mouse monoclonal IgG, C-2; Santa Cruz Biotechnology). In the immunoblot experiments, all antibodies gave clear signals at the predicted molecular sizes of the investigated proteins in total hippocampal lysates.

Protein extraction and immunoblot. Mice were killed at indicated time points after the training by cervical dislocation, their brains were removed, and hippocampi were dissected out. Individual hippocampi were collected and lysed in RIPA buffer containing protease and phosphatase inhibitors (50 mм Tris-HCl, pH 7.4, 1\% NP-40, 0.25\% Na-deoxycholate, $150 \mathrm{~mm} \mathrm{NaCl}, 1 \mathrm{~mm}$ EDTA, $1 \mathrm{~mm}$ PMSF, $1 \mu \mathrm{g} / \mathrm{ml}$ each aprotinin, leupeptin, and pepstatin, $1 \mathrm{~mm} \mathrm{Na} \mathrm{VO}_{4}$, and $1 \mathrm{~mm} \mathrm{NaF}$ ). The lysates were incubated for $15 \mathrm{~min}$ on ice and centrifuged for $15 \mathrm{~min}$ at $15,000 \times \mathrm{g}$, at $4^{\circ} \mathrm{C}$. The supernatants containing the protein extract were collected, and their protein concentration was determined by a Bio-Rad protein determination assay (Bio-Rad Laboratories, Hercules, CA). Duplicate samples of the hippocampal cell lysates ( $20 \mu \mathrm{g}$ per well) for individual mice were subjected to $10 \%$ SDS-PAGE and subsequently blotted to polyvinylidene difluoride membranes (Immobilon-P; Millipore, Bedford, MA) as described (Fischer et al., 2002). The membranes were saturated with I-block (Tropix) and then incubated with the anti-pErk-1/2 (diluted 1:8000), anti-Erk-1/2 (diluted 1:4000), anti-pp90Rsk-1 (diluted 1:1000), antip90Rsk-1 (diluted 1:500), anti-pMek-1/2 (diluted 1:1000), anti-Mek-1/2 (diluted 1:400), anti-actin (diluted 1:400), or anti-phospho-PKA, RII (diluted 1:200) for $1 \mathrm{hr}$ at room temperature. The membranes were subsequently incubated with the corresponding anti-rabbit or antimouse antibodies (1:5000-5001:10,000; Tropix), chemiluminescence enhancer (Nitro-block II; Tropix), and substrate (CDP Star; Tropix). Western blots were exposed to $\mathrm{x}$-ray films and developed in the range of maximal chemiluminescence emission (10 min). Signals were subsequently quantified by densitometric analyses using an IBM-based software (WinCam 2.2; Cybertech, Berlin, Germany). The densities of pMek-1/2, pErk-1/2, and pp90Rsk-1 were presented as normalized values to their total nonphosphorylated amounts or actin.

In situ hybridization. The specific primer pair 5'-GTCTGCTTGATGCTGTGG-3' and 5'-GCTTAGAGTCGACATGGA-3' were used to amplify a 1238 bp fragment of the cDNA sequence coding for $C R F_{2}$ by 
PCR. A hippocampal mouse cDNA library was used as template. The following thermocycle was used: $30 \mathrm{sec}$ at $94^{\circ} \mathrm{C}, 1 \mathrm{~min}$ at $65^{\circ} \mathrm{C}$, and 1.30 min at $72^{\circ} \mathrm{C}$. The corresponding fragment was introduced into a T/A cloning vector (pCRII; Invitrogen, San Diego, CA), and analyzed by DNA sequencing. By using EcoRI restriction sites, the fragment was subcloned into a pBluescript vector (Stratagene, La Jolla, CA). cRNA probes were generated by in vitro transcription using a UTP-digoxigeninlabeling kit for in vitro transcription (Roche, Basel, Switzerland). The corresponding sense and antisense probes were adjusted to an average length of 200 bp by limited alkaline hydrolysis (Van Pett et al., 2000). Microtome brain sections $15 \mu \mathrm{M}$ thick were fixed with $4 \%$ paraformaldehyde, followed by washing with PBS. The sections were then incubated for $5 \mathrm{~min}$ with $0.1 \mathrm{M}$ triethanolamine (TEA), followed by incubation with 0.1 м TEA containing $0.5 \%$ acetic anhydride. Prehybridization was performed by incubating the sections in hybridization buffer [ $50 \%$ formamide, $2 \%$ blocking agent (Roche), $0.02 \%$ SDS, $0.1 \%$ sarcosyl $/ 1 \times$ SSC] for $4 \mathrm{hr}$, following by hybridization with a digoxigenin-labeled probe diluted in hybridization buffer for $16 \mathrm{hr}$ at $50^{\circ} \mathrm{C}$. After hybridization, the sections were incubated with RNase A $(10 \mu \mathrm{g} / \mathrm{ml})$ and washed with $2 \times$ and $0.2 \times$ SSC. After washing, the sections were first incubated with $1 \%$ blocking agent/0.1 M maleic acid, followed by an alkaline phosphataseconjugated anti-digoxigenin antibody (Roche) diluted 1:2000 in 1\% blocking agent $/ 0.1 \mathrm{~m}$ maleic acid for $1 \mathrm{hr}$. Sections were washed several times and developed by the addition of 5-bromo-4-chloro-3-indolylphosphate/nitroblue tetrazolium. According to previous studies (Key et al., 2001), an optimal development time was used that ranged from 8 to $10 \mathrm{hr}$. Signals were densitometrically quantified by the NIH-image analysis system.

Data analysis. Statistical analysis was performed by unpaired Student's $t$ test or one-way ANOVA followed by Scheffe's test for post hoc comparison. The results are presented as mean $\pm \mathrm{SE}$.

\section{Results}

The hippocampal MAPK pathway is induced during memory consolidation of fear conditioning and stress-enhanced fear conditioning

To investigate the time course of Erk-1/2 phosphorylation after fear conditioning with and without stressful preexposure, $\mathrm{BALB} / \mathrm{c}$ mice were trained in the $\mathrm{FC}$ paradigm (FC group) or immobilized for $1 \mathrm{hr}$ and trained $3 \mathrm{hr}$ later (stress/FC group). Individual mice of each group ( $n=4$ per group) were killed 5,15 , 30,60 , or $120 \mathrm{~min}$ after training, and the ratio between hippocampal levels of pErk-1/2 and Erk-1/2 was determined by immunoblot. Naive mice served as controls. Significant timedependent increase of Erk-1/2 phosphorylation relative to the unphosphorylated protein was found in hippocampal lysates of mice of the FC group $\left(F_{(5,18)}=19.876 ; p<0.001\right)$ (Fig. 1 A). Post hoc analyses revealed significant increases 60 and $120 \mathrm{~min}$ after training, with a tendency toward a decrease at the $120 \mathrm{~min}$ time point. Similarly, Erk-1/2 phosphorylation relative to the unphosphorylated protein was strongly upregulated in mice of the stress/FC group $\left(F_{(5,18)}=73.791 ; p<0.001\right)$ (Fig. $\left.1 A\right)$. A significant increase was observed 30,60 , and $120 \mathrm{~min}$ after training (Fig. 1A,B).

It should be mentioned that additional pilot experiments were performed to determine the levels of pMek-1/2, pErk-1/2, and pp90Rsk-1 after immobilization without fear conditioning. It was found that the levels of these phosphoproteins were indistinguishable from their levels in naive mice at the time points $3 \mathrm{hr}$ $\left(t_{(1,8)}=0.545 ; p=0.447\right)$ and $4 \mathrm{hr}\left(t_{(1,8)}=0.245 ; p=0.338\right)$ after immobilization (data not shown). This result was in agreement with recent observations showing rapid dephosphorylation of Erk-1/2 after restraint stress (Pawlak et al., 2003). Thus, mice of the stress/FC group exhibited similarly low baseline levels of pMek-1/2, pErk-1/2, and pp90Rsk-1 as mice of the FC group before exposure to the training procedure.
A

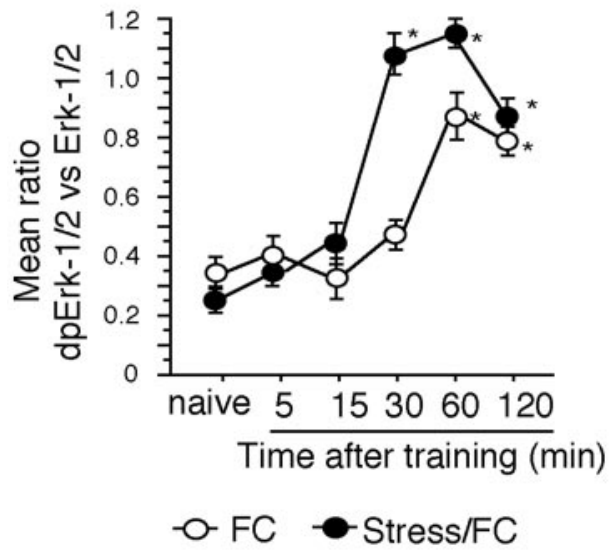

B

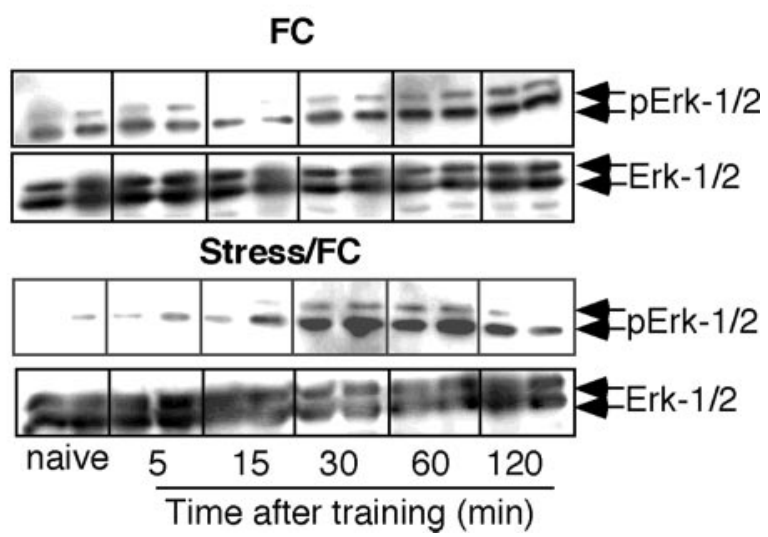

Figure 1. Activation of hippocampal Erk-1/2 after fear conditioning and stress-enhanced fear conditioning. A, Time course of Erk-1/2 phosphorylation after fear conditioning $(\mathrm{FC})$ and stress-enhanced fear conditioning (Stress/FC). In both groups, a significant upregulation of pErk-1/2 was observed $1 \mathrm{hr}$ after training. B, Representative immunoblots. Statistically significant differences: ${ }^{*} p<0.001$ versus naive mice.

Because in both FC and stress/FC groups pErk-1/2 reached maximal levels $1 \mathrm{hr}$ after the training, this time point was selected for further experiments as depicted in Figure $2 \mathrm{~A}$. FC and stress/FC groups were consisted of 15 mice each. Ten animals of each group were exposed to the conditioning context $24 \mathrm{hr}$ after training, and freezing behavior was scored. The remaining five mice per group were killed $1 \mathrm{hr}$ after training, and their hippocampi were dissected and used for immunoblot analysis of pMek-1/2, pErk-1/2, and pp90-Rsk-1.

Consistent with our previous observations, both FC and stress/FC groups froze significantly more than naive mice $\left(F_{(2,27)}=\right.$ 29.556; $p<0.001)$. Notably, the freezing of mice of the stress/FC group was significantly enhanced when compared with the freezing of the FC group (Fig. 2B). pMek-1/2 levels (Fig. 2C,D) in the FC group did not differ significantly from those detected in naive mice $\left(t_{(1,8)}=1.213 ; p=0.3326\right)$. Nevertheless, significant increases of pErk-1/2 $\left(t_{(1,8)}=26.015 ; p<0.01\right)$ and pp90Rsk-1 $\left(t_{(1,8)}=29.737\right.$; $p<0.01)$ were observed in the FC group when compared with the naive group (Fig. $2 C, D$ ). In mice of the stress/FC group, however, a significant upregulation of pMek-1/2 $\left(F_{(2,12)}=18.65 ; p<0.01\right)$ as well as pErk-1/2 $\left(F_{(2,12)}=31.216 ; p<0.001\right)$ and pp90Rsk-1 $\left(F_{(2,12)}\right.$ $=14.12 ; p<0.01)$ was observed when compared with the both naive and FC groups (Fig. 2C,D). These data showed that the levels of pErk-1/2 and pp90Rsk- 1 were increased after fear conditioning and further upregulated after stress-enhanced fear conditioning. Mek- 

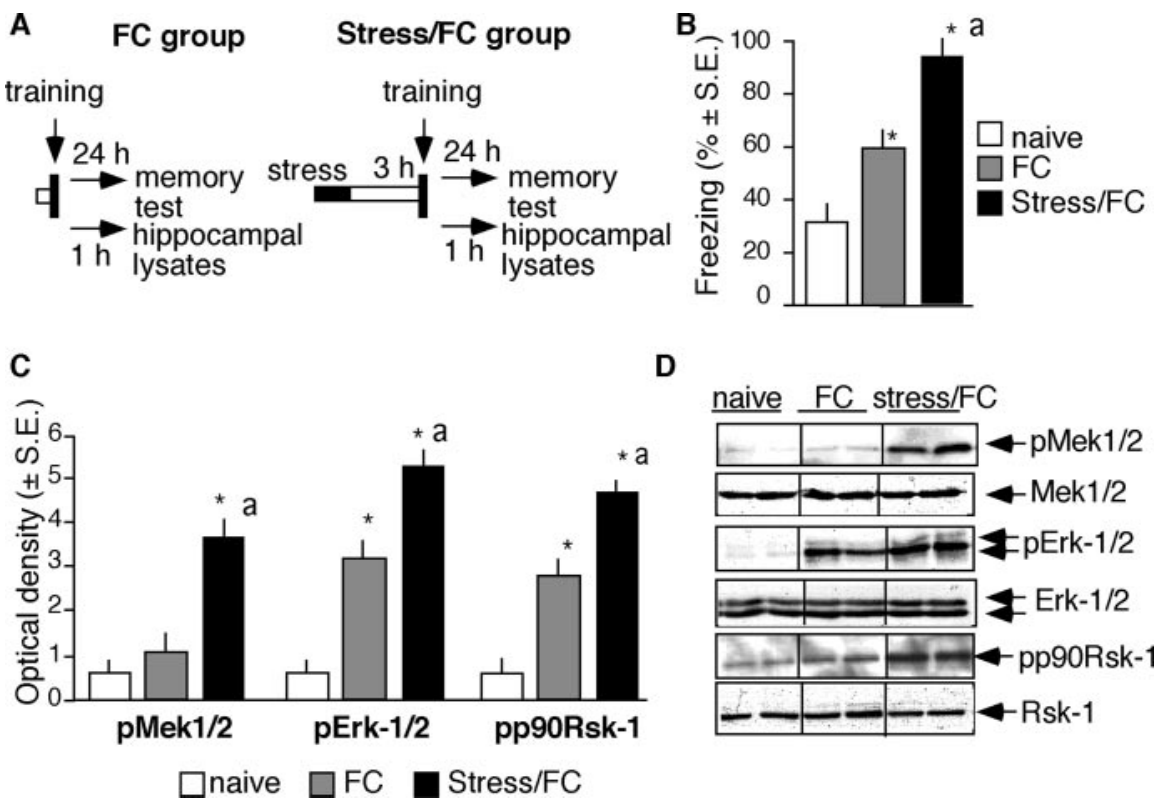

Figure 2. Activation of the hippocampal MAPK pathway after fear conditioning and stress-enhanced fear conditioning. $A$, Experimental design used in subsequent studies. Mice of the $F C$ group either were subjected $24 \mathrm{hr}$ after training to a memory test or killed $1 \mathrm{hr}$ after training to determine the activation of the MAP kinase pathway. Mice of the stress/FC group were treated identically except that training was performed $3 \mathrm{hr}$ after the end of $1 \mathrm{hr}$ immobilization. $B$, Mice of the stress/FC group froze significantly more than mice of the FC group during the contextual memory test. $C$, The level of pMek-1/2 was significantly increased in mice of the stress/FC, but not in mice of the FC group when compared with naive mice. pErk-1/2 and pp90 Rsk-1 were significantly upregulated in both FC and stress/FC groups; however, their levels in the stress/FC groups were significantly higher than both naive and FC groups. D, Representative immunoblots. Statistically significant differences: ${ }^{*} p<0.01$ versus naive; ${ }^{a} p<$ 0.01 versus $F C$ group.

$1 / 2$ protein phosphorylation was significantly induced only after stress-enhanced fear conditioning.

\section{PKA-dependent upregulation of pErk-1/2 and memory consolidation of fear conditioning and stress-enhanced fear conditioning}

PKA upregulates pErk-1/2 in hippocampal slices (Roberson et al., 1999) and in hippocampi of mice exposed to fear conditioning (Sananbenesi et al., 2002). Therefore, the role of PKA in memory consolidation and phosphorylation of pErk-1/2 was investigated by using FC and stress/FC groups of BALB/c mice as described above. Mice of the FC and stress/FC groups (14 per group) were given a hippocampal injection of the PKA inhibitor Rp-cAMPS (18 $\mu \mathrm{g}$ per mouse) or vehicle $15 \mathrm{~min}$ before training in the context-dependent fear-conditioning paradigm. Nine mice of each group were exposed to the conditioning context $24 \mathrm{hr}$ later, whereas five mice of each group were used to determine hippocampal pErk-1/2 levels $1 \mathrm{hr}$ after training (Fig. 3A).

Freezing behavior, determined $24 \mathrm{hr}$ after training, was significantly reduced in the FC-Rp-cAMPS group when compared with the FC-vehicle group $\left(F_{(3,36)}=14.482 ; p<0.001\right)$, demonstrating that PKA activity was required for context-dependent fear conditioning of BALB/c mice (Fig. 3B). RpcAMPS also significantly impaired stress-enhanced memory consolidation, as indicated by significantly reduced freezing of the stress/FC-RpcAMPS group $(p<0.001)$ when compared with the stress/FCvehicle group (Fig. $3 \mathrm{~B}$ ). Injection of Rp-cAMPS significantly decreased the levels of pErk-1/2 $\left(F_{(3,16)}=14.164 ; p<0.01\right)$ in both FC-Rp-cAMPS and stress/FC-Rp-cAMPS groups when compared with their corresponding vehicle controls (Fig. $3 C, D$ ).

These results indicated that PKA is likely to be involved in mem- ory consolidation and Erk-1/2 phosphorylation during fear conditioning and possibly stress-enhanced fear conditioning.

Mek-1/2 mediates the upregulation of pErk-1/2 and memory consolidation of stress-enhanced fear conditioning On the basis of the data demonstrating a selective upregulation of pMek-1/2 after stress-enhanced fear conditioning (Fig. $2 C, D)$, it was assumed that inhibition of Mek1/2 activity might prevent the enhancement of fear conditioning by stress. To test this possibility, FC and stress/FC groups of mice (13 per group) were given a hippocampal injection of U0126 ( $1 \mu \mathrm{g}$ per mouse) or vehicle and trained 15 min later. Eight mice per group were reexposed to the conditioning context $24 \mathrm{hr}$ later, whereas hippocampi of five mice per group were collected $1 \mathrm{hr}$ after training.

Inhibition of Mek-1/2 significantly reduced freezing of mice of the stress/FCU0126 group when compared with its vehicle control $\left(F_{(3,28)}=5.004 ; p<0.01\right)$; however, freezing of the FC-U0126 group was similar ( $p=0.7965)$ to the $\mathrm{FC}-$ vehicle control (Fig. 4A). Because freezing behavior was not affected by pretraining administration of U0126 in mice of the FC group, possible nonspecific effects of the inhibitor could be excluded.

Notably, injection of U0126 had no effect on pErk-1/2 during memory consolidation of conditioned fear, as indicated by indistinguishable levels of pErk-1/2 $(p=0.805)$ in hippocampal lysates of the FC-vehicle and FC-U0126 groups (Fig. $4 B, C$ ). In contrast, the hippocampal level of pErk-1/2 was significantly reduced in the stress/FC-U0126 group $\left(F_{(3,16)}=5.52 ; p<0.05\right)$ when compared with the stress/FC-vehicle group (Fig. $4 B, C$ ).

These data showed that Mek-1/2 was involved in Erk phosphorylation elicited by stress-enhanced fear conditioning but not fear conditioning without previous stressful experience.

\section{Hippocampal $\mathrm{CRF}_{2}$ is upregulated by acute stress}

To determine whether hippocampal $\mathrm{CRF}_{2}$ was involved in the observed behavioral and molecular effects of stress on fear conditioning, we first investigated whether stressful immobilization influenced the expression of hippocampal $C R F_{2}$ mRNA. BALB/c mice (three per group) were immobilized for $1 \mathrm{hr}$ and killed 0.5 , 3 , or 24 hr later. The expression of the $\mathrm{CRF}_{2}$ gene was detected by in situ hybridization. Naive mice (three per group) were used as control.

In agreement with previous findings (Van Pett et al., 2000) the mRNA for $\mathrm{CRF}_{2}$ was found within the hippocampal regions CA1 and CA3 and the dentate gyrus of all experimental groups. At the time point $3 \mathrm{hr}$ after the end of stressful immobilization, the $C R F_{2}$ gene was significantly upregulated $\left(F_{(3,8)}=37.417 ; p<0.001\right)$ when compared with naive mice, whereas its levels were back to baseline values after $24 \mathrm{hr}$ (Fig. $5 A, B$ ). $C R F_{2}$ expression in the lateral septum, the most prominent site of $C R F_{2}$ expression, did not show significant changes at the same time points (data not shown). 
A

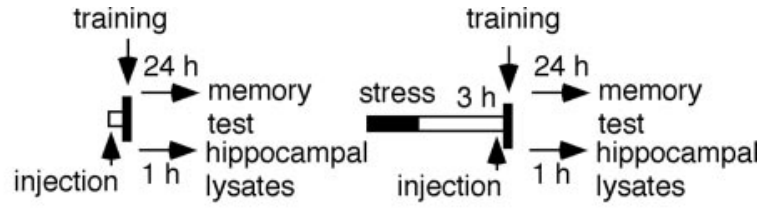

B
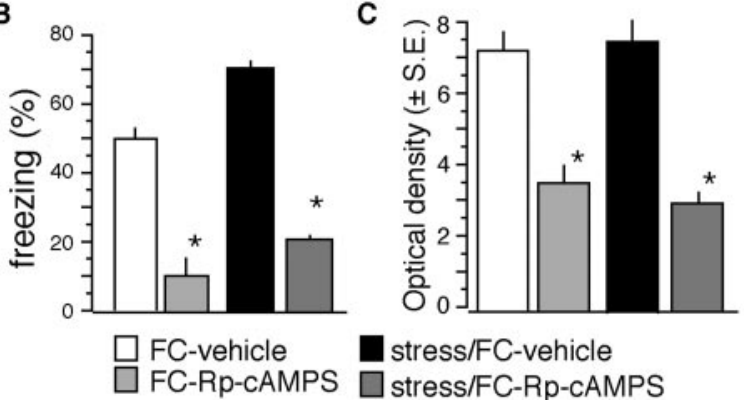

D

FC vehicle Rp-cAMPS vehicle Rp-cAMPS

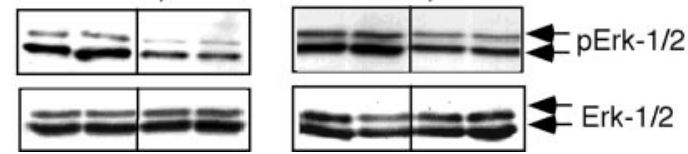

Figure 3. PKA-dependent upregulation of pErk-1/2 in response to fear conditioning. $A$, Experimental design. Injection of the PKA inhibitor Rp-cAMPS (18 $\mu \mathrm{g}$ per mouse) into the dorsal hippocampus was performed 15 min before the context-dependent fear conditioning of mice of the $\mathrm{FC}$ and stress/FC groups. B, Rp-CAMPS significantly reduced freezing behavior when compared with vehicle-injected animals. C, Mice injected intrahippocampally with Rp-cAMPS exhibited significantly lower $p$ Erk-1/2 levels than vehicle-injected animals. $D$, Representative immunoblots. Statistically significant differences: ${ }^{*} p<0.01$ versus corresponding $\mathrm{FC}-$ or stress/FC-vehicle group.
A

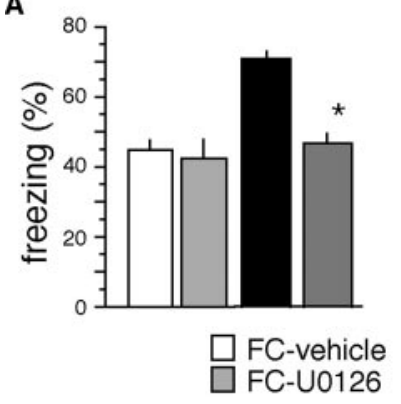

B

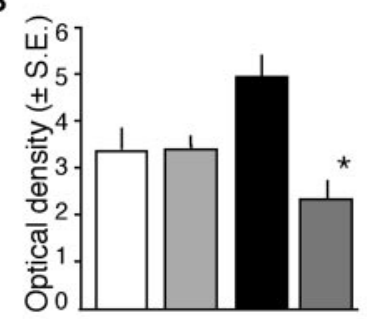

stress/FC-vehicle stress/FC-U0126
C

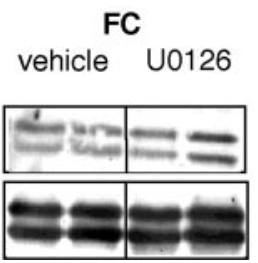

Stress/FC vehicle U0126

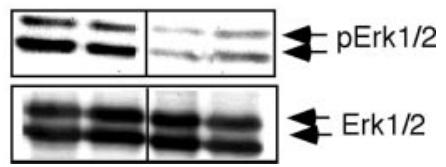

Figure 4. Mek-1/2 activity mediates stress-enhanced Erk-1/2 phosphorylation and fear conditioning. Vehicle or U0126 (1 $\mu \mathrm{g}$ per mouse) were injected intrahippocampally $15 \mathrm{~min}$ before the training as described in Figure $3 A$. $A$, Intrahippocampal injection of $U 0126$ prevented freezing behavior of the stress/FC group without affecting freezing of the $\mathrm{FC}$ group. $B$, Mice of the stress/FC group injected intrahippocampally with U0126 exhibited significantly lower pErk-1/2 levels than vehicle-injected animals. U0126 did not affect pErk-1/2 levels in mice of the FC group. C, Representative immunoblots. Statistically significant differences: ${ }^{*} p<0.01$ versus stress/FC-vehicle group.
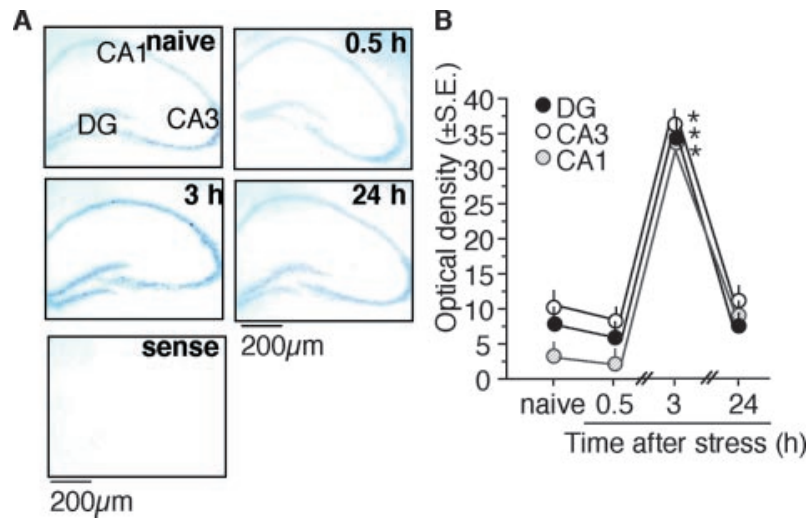

Figure 5. Hippocampal $C R F_{2}$ is induced by acute immobilization. $A, B A L B / c$ mice (three per group) were immobilized for $1 \mathrm{hr}$, and brain section were prepared for in situ hybridization at the time points $0.5,3$, and $24 \mathrm{hr}$ after the end of immobilization. Representative hippocampal micrographs of the in situ hybridizations using an antisense probe for $C R F_{2}$ are shown. $B$, Quantified signals for hippocampal $C R F_{2}$ mRNA. A significant upregulation of $C R F_{2}$ mRNA was observed within the hippocampal subregions CA1 and CA3 and the dentate gyrus (DG) at the time point $3 \mathrm{hr}$ after the end of immobilization. Statistically significant differences: ${ }^{*} p<0.01$ versus naive mice.
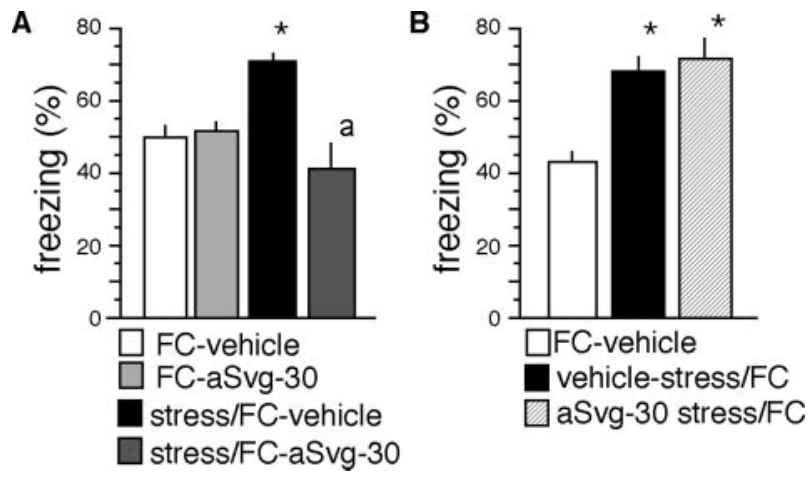

Figure 6. aSvg-30 prevents stress-enhanced fear conditioning. $A$, Intrahippocampal microinfusion of aSvg-3015 min before training (as described in Fig. 2A) significantly reduced freezing of mice of the stress/FC group when compared with their vehicle controls; however, aSvg-30 did not affect freezing behavior of mice of the $F($ group. $B$, Intrahippocampal microinfusion of aSvg-30 15 min before immobilization ( $4 \mathrm{hr}$ before training) did not affect freezing of mice of the stress/FC group. Statistically significant differences: ${ }^{*} p<0.01$ versus $F(-$ vehicle group; ${ }^{a} p<0.01$ versus stress/FC-vehicle group.

Hippocampal $\mathrm{CRF}_{2}$ activates the hippocampal Mek-1/2 pathway and mediates stress-enhanced fear conditioning The role of $\mathrm{CRF}_{2}$ in fear conditioning and stress-enhanced fear conditioning was investigated by intrahippocampal application of the highly selective $\mathrm{CRF}_{2}$ antagonist aSvg-30 (400 ng/0.5 $\mu \mathrm{l}$ per mouse). The selectivity of aSvg-30 for $\mathrm{CRF}_{2}$ but not $\mathrm{CRF}_{1}$ was demonstrated in vitro by binding studies and functional assays (Ruhmann et al., 1998). In addition, in vivo experiments show that aSvg-30 does not interfere with $\mathrm{CRF}_{1}$-mediated effects (Radulovic et al., 1999; Martinez et al., 2002; Pelleymounter et al., 2002; Hammack et al., 2003; Lu et al., 2003). BALB/c mice (nine per group) were assigned to $\mathrm{FC}$ and stress/FC groups as described above and were given intrahippocampal injections of aSvg-30 or vehicle $15 \mathrm{~min}$ before training. During the memory test performed $24 \mathrm{hr}$ later (Fig. 6A), the freezing behavior of the FCaSvg-30 group and FC-vehicle group did not differ from one another $\left(t_{(1,16)}=0.994 ; p=0.3336\right)$. In contrast, the freezing behavior of the stress/FC-aSvg-30 group was significantly decreased $\left(t_{(1,16)}=7.185 ; p<0.05\right)$ when compared with the stress/ 

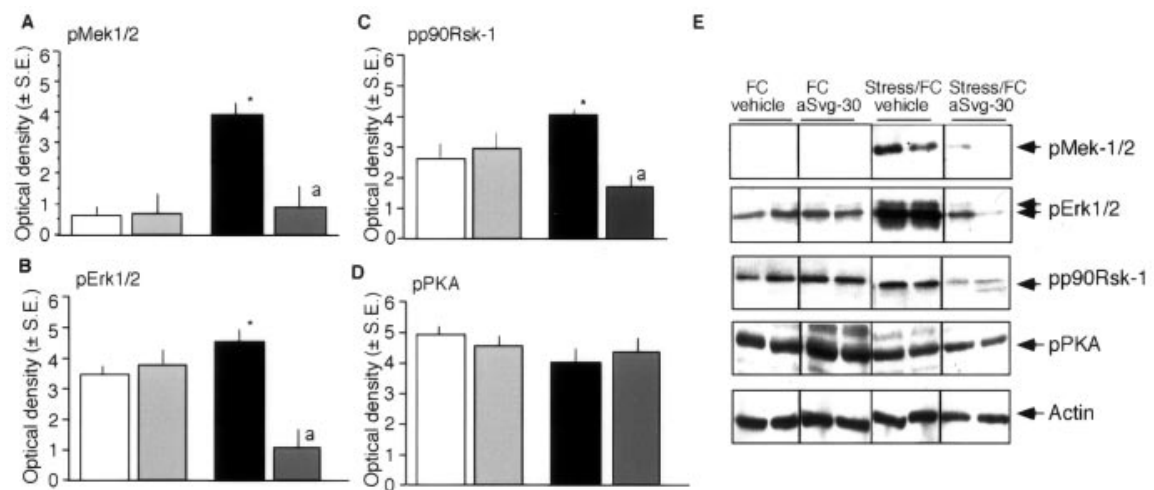

$\square$ FC-vehicle $\square$ FC-aSvg-30

Stress/FC-vehicle
Figure 7. aSvg-30 prevents the upregulation of the hippocampal MAP Kinase pathway after stress-enhanced fear conditioning. Intrahippocampal microinfusion of aSvg-30 15 min before training significantly reduced pMek-1/2 $(A)$, EErk-1/2 (B), and pp90Rsk-1 ( $C$ ) levels in the stress/FC group without affecting the phosphorylation of the PKA regulatory subunit II (D) when compared with the stress/FC-vehicle group. The levels of pMek-1/2 $(A)$, pErk-1/2 (B), pp90Rsk-1 (C), and pPKA (D) were not affected by aSvg-30 injections in mice of the FC group. $E$, Representative immunoblots. Actin immunostaining was used to control for the total protein amount among samples. Statistically significant differences: ${ }^{*} p<0.01$ versus $\mathrm{FC}-$ vehicle group; ${ }^{a} p<0.01$ versus stress/FC-vehicle group.

FC-vehicle group (Fig. 6A). In an additional experiment, aSvg-30 was injected 15 min before immobilization, and $3 \mathrm{hr}$ later the mice were trained in the fear-conditioning paradigm. Application of aSvg-30 before immobilization did not prevent stressenhanced fear conditioning, as revealed by significantly higher freezing levels $\left(F_{(2,18)}=10.813 ; p<0.001\right)$ of aSvg-30- and vehicle-injected stress/FC groups when compared with the FCvehicle group (Fig. 6B).

Thus, aSvg-30 selectively prevented the stress-induced enhancement of fear conditioning without affecting the fear conditioning of nonstressed mice. On this basis, possible nonspecific effects of aSvg-30 on freezing behavior could be excluded. Moreover, aSvg-30 was effective $3 \mathrm{hr}$ after but not before immobilization.

To test whether hippocampal $\mathrm{CRF}_{2}$ contributed to the upregulation of the MAPK signaling pathway, experimental groups were set up as described above (FC-vehicle, FC-aSvg-30, stress/ FC-vehicle, stress/FC-aSvg-30), and hippocampal protein lysates were prepared $1 \mathrm{hr}$ later. No significant differences of hippocampal pMek1/2 $\left(t_{(1,8)}=2.074 ; p=0.2233\right)$, pErk-1/2 $\left(t_{(1,8)}=\right.$ $0.13 ; p=0.9156)$, and pp90Rsk-1 $\left(t_{(1,8)}=0.295 ; p=0.6156\right)$ were observed between the FC-vehicle and FC-aSvg-30 groups (Fig. 7A-C, E). In contrast, mice of the stress/FC-aSvg-30 group exhibited significantly lower pMek-1/2 $\left(t_{(1,8)}=12.633\right.$; $\left.p<0.01\right)$, pErk-1/2 $\left(t_{(1,8)}=10.713 ; p<0.01\right)$, and pp90Rsk-1 $\left(t_{(1,8)}=\right.$ $16.268 ; p<0.01)$ levels when compared with the corresponding vehicle group. Notably, the phosphorylation of the PKA regulatory subunit II was not affected $\left(t_{(1,8)}=0.015 ; p=0.9126\right)$ by aSvg-30 (Fig. $7 D, E$ ). Taken together, these results showed that the hippocampal $\mathrm{CRF}_{2}$ contributed to upregulation of the hippocampal MAPK pathway after fear conditioning of stressed mice via activation of Mek-1/2.

\section{Discussion}

In the present study, it was demonstrated that hippocampal Erk/ MAPK signaling during fear conditioning depended on PKA, whereas Mek-dependent Erk/MAPK signaling was induced when mice experienced an acute stress before fear conditioning. It was demonstrated previously that hippocampal pErk-1/2 levels rise after context-dependent fear conditioning (Atkins et al., 1998;
Sananbenesi et al., 2002). The activation of Erk-1/2 (Atkins et al., 1998) and its downstream targets Elk-1 and p90Rsk-1 (Sananbenesi et al., 2002) is specific for associative learning, as revealed by lower levels of these phosphoproteins in mice trained with a paired context-shock presentation than after control conditions consisting of contextual or immediate shock exposure. In agreement with these studies, elevated hippocampal pErk-1/2 and pp90Rsk-1 were detected after fear conditioning of nonstressed mice. Interestingly, even stronger upregulation of pErk-1/2 and pp90Rsk- 1 was found when fear conditioning was performed $3 \mathrm{hr}$ after immobilization, supporting the view that acute stressful experience interfered with molecular pathways underlying memory consolidation. The phosphorylation of Erk-1/2 and pp90Rsk-1 as well as acquisition of conditioned fear depended on PKA but not Mek-1/2 activity, as revealed by full abolition of the behavioral and molecular changes by the PKA inhibitor Rp-cAMPS and lack of effect by the Mek-1/2 inhibitor U0126. Erk-1/2 represents a molecular target of multiple hippocampal signaling cascades involving PKA, PKC, and Mek-1/2 (Atkins et al., 1998; Roberson et al., 1999). In view of those findings as well as increasing evidence showing Mek-1/2-independent phosphorylation of Erk-1/2 involving PKA or PKC (Grammer and Blenis, 1997; Choe and McGinty, 2000; Bapat et al., 2001; Kinkl et al., 2001), the observed contribution of PKA in Erk-1/2 phosphorylation during fear conditioning was not surprising. It should be mentioned, however, that inhibition of Mek-1/2 in the CA1 hippocampal subfield was found previously to prevent Erk-1/2 phosphorylation induced by fear conditioning (Athos et al., 2002). Whether this discrepancy is a result of the mouse strain, the injection site, or differences in the fear-conditioning procedure remains to be elucidated. Nevertheless, Mek-1/2 was strongly activated when fear conditioning was performed after immobilization, suggesting that stronger stimulus was required for Mek-1/2-dependent increase of pErk-1/2. This interpretation is supported by studies demonstrating that Mek-1/2-mediated phosphorylation of Erk-1/2 significantly depends on the stimulus properties applied to induce long-term potentiation in hippocampal slices of mice (Winder et al., 1999; Selcher et al., 2003).

A possibility remains that PKA also contributed to the molecular and behavioral changes elicited by immobilization. In agreement with previous studies (Abel et al., 1997), PKA was clearly involved in fear conditioning. Therefore, it was not possible to selectively delineate its effects in stress-enhanced fear conditioning. It also remains to be elucidated which receptors trigger PKA activation during fear conditioning of nonstressed BALB/c mice. An involvement of CRF receptors does not seem probable taking into account that aSvg-30 (Fig. 6A) and astressin (Radulovic et al., 1999) did not affect fear conditioning of BALB/c mice if a stressful preexposure was omitted.

Consistent with our previous findings (Radulovic et al., 1999), exposure of BALB/c mice to a $1 \mathrm{hr}$ immobilization resulted in a significant enhancement of associative learning when mice were trained $3 \mathrm{hr}$ later in the fear-conditioning paradigm. This effect depended on the activation of hippocampal CRF receptors, as 
demonstrated by the finding that intrahippocampal infusion of the nonselective CRF receptor antagonist astressin before or $3 \mathrm{hr}$ after the end of immobilization prevented the enhancement of fear conditioning (Radulovic et al., 1999). In line with those data, aSvg-30, the selective $\mathrm{CRF}_{2}$ antagonist, also prevented stressenhanced fear conditioning; however, in contrast to astressin, aSvg-30 was effective only $3 \mathrm{hr}$ after the end of stress and shortly before training. On this basis it was indicated that early $\mathrm{CRF}_{1}$ and delayed $\mathrm{CRF}_{2}$ mediated molecular mechanisms contributed to the overall enhancement of fear conditioning by acute stressful experience. These effects are similar to the delayed $\mathrm{CRF}_{2}$ actions during urocortin-induced suppression of feeding behavior (Coste et al., 2000) and urocortin-mediated anxiolysis (Valdez et al., 2002). The delayed involvement of $\mathrm{CRF}_{2}$ in stress effects on learning coincided with a significant upregulation of $C R F_{2}$ mRNA $3 \mathrm{hr}$ after the end of stress, but not at earlier time points. Importantly, training at earlier time points after immobilization does not affect fear conditioning (Radulovic et al., 1999), suggesting that increased expression of $C R F_{2}$ mRNA might have contributed to stress-enhanced associative learning. This view is also supported by the finding that $\mathrm{CRF}_{2}$ was not involved in fear conditioning without previous immobilization, as revealed by the inability of intrahippocampally injected aSvg-30 to modulate freezing behavior. It should be mentioned that although the presented data point to a role of $\mathrm{CRF}_{2}$, an involvement of $\mathrm{CRF}_{1}$ in the delayed effects of stress on fear conditioning is not excluded.

$\mathrm{CRF}_{2}$ significantly contributed to the Mek-1/2-dependent upregulation of pErk-1/2 and its downstream target pp90Rsk-1, as revealed by the ability of intrahippocampally injected aSvg-30 to prevent Mek-1/2, Erk-1/2, and p90Rsk-1 phosphorylation without affecting the phosphorylation of the PKA regulatory subunit II $\alpha$ in the model of stress-enhanced learning. Thus, $\mathrm{CRF}_{2}$ appeared to be selectively coupled to Mek-1/2- but not to PKAdependent phosphorylation of Erk-1/2 and p90Rsk-1. Whether hippocampal $\mathrm{CRF}_{2}$ protein levels may be too low to interfere with fear conditioning and PKA signaling of nonstressed mice remains to be elucidated.

In addition to hippocampal $\mathrm{CRF}_{2}$, dorsal raphe $\mathrm{CRF}_{2}$ may also be involved in stress-mediated enhancement of fear conditioning (Hammack et al., 2003). On the other hand, $\mathrm{CRF}_{2}$ within the lateral septum impairs fear conditioning of nonstressed mice (Radulovic et al., 1999). The role of CRF receptors in associative learning depends on their regional interactions with other G-protein-coupled receptors (Radulovic et al., 2000). It can be expected, therefore, that $\mathrm{CRF}_{2}$ may activate distinct molecular pathways in different brain areas. This view is consistent with earlier observations showing selective regional alterations of cAMP response element-binding protein phosphorylation in the forebrain of mice lacking $\mathrm{CRF}_{2}$ (Kishimoto et al., 2000) that involved the amygdala but not the hippocampus.

In conclusion, we identified a molecular pathway underlying the delayed effects of acute stressful experience on memory consolidation involving hippocampal $\mathrm{CRF}_{2}$ and Mek-1/2 signaling. On this basis, it is proposed that stress-induced $\mathrm{CRF}_{2}$ could selectively enhance the consolidation of aversive memories after acute stressful events by interfering with molecular processes underlying long-term memory storage.

\section{References}

Abel T, Nguyen PV, Barad M, Deuel TA, Kandel ER, Bourtchouladze R (1997) Genetic demonstration of a role for PKA in the late phase of LTP and in hippocampus-based long-term memory. Cell 88:615-626.

Athos J, Impey S, Pineda VV, Chen X, Storm DR (2002) Hippocampal CRE- mediated gene expression is required for contextual memory formation. Nat Neurosci 5:1119-1120.

Atkins CM, Selcher JC, Petraitis JJ, Trzaskos JM, Sweatt JD (1998) The MAPK cascade is required for mammalian associative learning. Nat Neurosci 1:602-609.

Bapat S, Verkleij A, Post JA (2001) Peroxynitrite activates mitogenactivated protein kinase (MAPK) via a MEK-independent pathway: a role for protein kinase C. FEBS Lett 499:21-26.

Behan DP, Heinrichs SC, Troncoso JC, Liu XJ, Kawas CH, Ling N, De Souza EB (1995) Displacement of corticotropin releasing factor from its binding protein as a possible treatment for Alzheimer's disease. Nature 378:284-287.

Blank T, Nijholt I, Grammatopoulos DK, Randeva HS, Hillhouse EW, Spiess J (2003) Corticotropin-releasing factor receptors couple to multiple G-proteins to activate diverse intracellular signaling pathways in mouse hippocampus: role in neuronal excitability and associative learning. J Neurosci 23:700-707.

Cano E, Mahadevan L (1995) Parallel signal processing among mammalian MAPKs. Trends Biochem Sci 20:117-122.

Chen RH, Sarnecki C, Blenis J (1992) Nuclear localization and regulation of Erk- and Rsk-encoded protein kinases. Mol Cell Biol 12:915-927.

Choe ES, McGinty JF (2000) N-methyl-D-aspartate receptors and p38 mitogen-activated protein kinase are required for cAMP-dependent cyclase response element binding protein and Elk-1 phosphorylation in the striatum. Neuroscience 101:607-617.

Coste SC, Kesterson RA, Heldwein KA, Stevens SL, Heard AD, Hollis JH, Murray SE, Hill JK, Pantely GA, Hohimer AR, Hatton DC, Phillips TJ, Finn DA, Low MJ, Rittenberg MB, Stenzel P, Stenzel-Poore MP (2000) Abnormal adaptations to stress and impaired cardiovascular function in mice lacking corticotropin-releasing hormone receptor-2. Nat Genet 24:403-409.

De Souza EB (1995) Corticotropin-releasing factor receptors: physiology, pharmacology, biochemistry and role in central nervous system and immune disorders. Psychoneuroendocrinology 20:789-819.

Eckart K, Jahn O, Radulovic J, Radulovic M, Blank T, Stiedl O, Brauns O, Tezval H, Zeyda T, Spiess J (2002) Pharmacology and biology of corticotropin-releasing factor (CRF) receptors. Receptors Channels 8:163-177.

Elliott-Hunt CR, Kazlauskaite J, Wilde GJ, Grammatopoulos DK, Hillhouse EW (2002) Potential signaling pathways underlying corticotrophinreleasing hormone-mediated neuroprotection from excitotoxicity in rat hippocampus. J Neurochem 80:416-425.

Fischer A, Sananbenesi F, Schrick C, Spiess J, Radulovic J (2002) Cyclindependent kinase 5 is required for associative learning. J Neurosci 22:3700-3707.

Fischer A, Sananbenesi F, Schrick C, Spiess J, Radulovic J (2003) Regulation of contextual fear conditioning by baseline and inducible septohippocampal cyclin-dependent kinase 5. Neuropharmacology 44:1089-1099.

Grammer TC, Blenis J (1997) Evidence for MEK-independent pathways regulating the prolonged activation of the ERK-MAP kinases. Oncogene 14:1635-1642.

Hammack SE, Schmid MJ, LoPresti ML, Der-Avakian A, Pellymounter MA, Foster AC, Watkins LR, Maier SF (2003) Corticotropin releasing hormone type 2 receptors in the dorsal raphe nucleus mediate the behavioral consequences of uncontrollable stress. J Neurosci 23:1019-1025.

Hsu SY, Hsueh AJW (2001) Human stresscopin and stresscopin-related peptide are selective ligands for the type 2 corticotropin-releasing hormone receptor. Nat Med 7:605-611.

Impey S, Obrietan K, Wong ST, Poser S, Yano S, Wayman G, Deloulme JC, Chan G, Storm DR (1998) Cross talk between ERK and PKA is required for $\mathrm{Ca}^{2+}$ stimulation of CREB-dependent transcription and ERK nuclear translocation. Neuron 21:869-883.

Kandel ER (2001) The molecular biology of memory storage: a dialogue between genes and synapses. Science 294:1030-1038.

Key M, Wirick B, Cool D, Morris M (2001) Quantitative in situ hybridization for peptide mRNAs in mouse brain. Brain Res Protoc 8:8-15.

Kinkl N, Sahel J, Hicks D (2001) Alternate FGF2-ERK1/2 signaling pathways in retinal photoreceptor and glial cells in vitro. J Biol Chem 276:43871-43878.

Kishimoto T, Radulovic J, Radulovic M, Lin CR, Schrick C, Hooshmand F, Hermanson O, Rosenfeld MG, Spiess J (2000) Deletion of crhr2 reveals 
an anxiolytic role for corticotropin-releasing hormone receptor-2. Nat Genet 24:415-419.

Lewis K, Li C, Perrin MH, Blount A, Kunitake K, Donaldson C, Vaughan J, Reyes TM, Gulyas J, Fischer W, Bilezikjian L, Rivier J, Sawchenko PE, Vale WW (2001) Identification of urocortin III, an additional member of the corticotropin-releasing factor (CRF) family with high affinity for the CRF2 receptor. Proc Natl Acad Sci USA 98:7570-7575.

Lu L, Liu Z, Huang M, Zhang (2003) Dopamine-dependent responses to cocaine depend on corticotropin-releasing factor receptor subtypes. J Neurochem 84:1378-1386.

Martinez V, Wang L, Rivier JE, Vale W, Tache Y (2002) Differential actions of peripheral corticotropin-releasing factor (CRF), urocortin II, and urocortin III on gastric emptying and colonic transit in mice: role of CRF receptor subtypes 1 and 2. J Pharmacol Exp Ther 301:611-617.

Matynia A, Anagnostaras SG, Silva AJ (2001) Weaving the molecular and cognitive strands of memory. Neuron 32:557-559.

Milanovic S, Radulovic J, Laban O, Stiedl O, Henn F, Spiess J (1998) Production of the Fos protein after contextual fear conditioning of C57BL/6N mice. Brain Res 784:37-47.

Pawlak R, Magarinos AM, Melchor J, McEwen B, Strickland S (2003) Tissue plasminogen activator in the amygdala is critical for stress-induced anxiety-like behavior. Nat Neurosci 6:168-174.

Pedersen WA, Wan R, Zhang P, Mattson MP (2002) Urocortin, but not urocortin II, protects cultured hippocampal neurons from oxidative and excitotoxic cell death via corticotropin-releasing hormone receptor type I. J Neurosci 22:404-412.

Pelleymounter MA, Joppa M, Ling N, Foster AC (2002) Evidence supporting a role for central corticotropin-releasing factor(2) receptors in behavioral, but not endocrine, response to environmental stress. J Pharmacol Exp Ther 302:145-152.

Radulovic J, Kammermeier J, Spiess J (1998) Relationship between fos production and classical fear conditioning: effects of novelty, latent inhibition, and unconditioned stimulus preexposure. J Neurosci 18:7452-7461.

Radulovic J, Ruhmann A, Liepold T, Spiess J (1999) Modulation of learning and anxiety by corticotropin-releasing factor (CRF) and stress: differential roles of CRF receptors 1 and 2. J Neurosci 19:5016-5025.

Radulovic J, Fischer A, Katerkamp U, Spiess J (2000) Role of regional neurotransmitter receptors in corticotropin-releasing factor (CRF)-mediated modulation of fear conditioning. Neuropharmacology 39:707-710.

Radulovic M, Hippel C, Spiess J (2003) Corticotropin-releasing factor (CRF) rapidly suppresses apoptosis by acting upstream of the activation of caspases. J Neurochem 84:1074-1085.

Reyes TM, Lewis K, Perrin MH, Kunitake KS, Vaughan J, Arias CA, Hogenesch JB, Gulyas J, Rivier J, Vale WW, Sawchenko PE (2001) Urocortin II: a member of the corticotropin-releasing factor (CRF) neuropeptide family that is selectively bound by type 2 CRF. Proc Natl Acad Sci USA 98:2843-2848.

Roberson ED, English JD, Adams JP, Selcher JC, Kondratick C, Sweatt JD (1999) The mitogen-activated protein kinase cascade couples PKA and PKC to cAMP response element binding protein phosphorylation in area CA1 of hippocampus. J Neurosci 19:4337-4348.

Roozendaal B, Brunson KL, Holloway BL, McGaugh JL, Baram TZ (2002) Involvement of stress-released corticotropin-releasing hormone in the basolateral amygdala in regulating memory consolidation. Proc Natl Acad Sci USA 99:13908-13913.

Rossant CJ, Pinnock RD, Hughes J, Hall MD, McNulty S (1999)
Corticotropin-releasing factor type 1 and type 2 alpha receptors regulate phosphorylation of calcium/cyclic adenosine $3^{\prime}, 5^{\prime}$-monophosphate response element-binding protein and activation of p42/p44 mitogenactivated protein kinase. Endocrinology 140:1525-1536.

Ruhmann A, Bonk I, Lin CR, Rosenfeld MG, Spiess J (1998) Structural requirements for peptidic antagonists of the corticotropin-releasing factor receptor (CRFR): development of CRFR2beta-selective antisauvagine-30. Proc Natl Acad Sci USA 95:15264-15269.

Sananbenesi F, Fischer A, Schrick C, Spiess J, Radulovic J (2002) Phosphorylation of hippocampal Erk-1/2, Elk-1, and p90-Rsk-1 during contextual fear conditioning: interactions between Erk-1/2 and Elk-1. Mol Cell Neurosci 21:463-476.

Schafe GE, Atkins CM, Swank MW, Bauer EP, Sweatt JD, LeDoux JE (2000) Activation of ERK/MAP kinase in the amygdala is required for memory consolidation of Pavlovian fear conditioning. J Neurosci 20:8177-8187.

Selcher JC, Weeber EJ, Christian J, Nekrasova T, Landreth GE, Sweatt JD (2003) A role for ERK MAP kinase in physiologic temporal integration in hippocampal area CA1. Learn Mem 10:26-39.

Shors TJ, Weiss C, Thompson RF (1992) Stress-induced facilitation of classical conditioning. Science 24:537-539.

Smith MA, Makino S, Kvetnansky R, Post RM (1995) Stress and glucocorticoids affect the expression of brain-derived neurotrophic factor and neurotrophin-3 mRNAs in the hippocampus. J Neurosci 15:1961-1970.

Spiess J, Rivier J, Rivier C, Vale W (1981) Primary structure of corticotropin-releasing factor from ovine hypothalamus. Proc Natl Acad Sci USA 78:6517-6521.

Stanciu M, Radulovic J, Spiess J (2000) Phosphorylated cAMP response element binding protein in the mouse brain after fear conditioning: relationship to Fos production. Mol Brain Res 94:15-24.

Sweatt JD (2001) The neuronal MAP kinase cascade: a biochemical signal integration system subserving synaptic plasticity and memory. J Neurochem 76:1-10.

Valdez GR, Inoue K, Koob GF, Rivier J, Vale W, Zorrilla EP (2002) Human urocortin II: mild locomotor suppressive and delayed anxiolytic-like effects of a novel corticotropin-releasing factor related peptide. Brain Res 943:142-150.

Vale W, Spiess J, Rivier C, Rivier J (1981) Characterization of a 41-residue ovine hypothalamic peptide that stimulates secretion of corticotropin and $\beta$-endorphin. Science 213:1394-1397.

Van Pett K, Viau V, Bittencourt JC, Chan RK, Li HY, Arias C, Prins GS, Perrin M, Vale W, Sawchenko PE (2000) Distribution of mRNAs encoding CRF receptors in brain and pituitary of rat and mouse. J Comp Neurol 428:191-212.

Vaughan J, Donaldson C, Bittencourt J, Perrin MH, Lewis K, Sutton S, Chan R, Turnbull AV, Lovejoy D, Rivier C, Rivier J, Sawchenko PE, Vale W (1995) Urocortin, a mammalian neuropeptide related to fish urotensin I and to corticotropin-releasing factor. Nature 378:287-292.

Winder DG, Martin KC, Muzzio IA, Rohrer D, Chruscinski A, Kobilka B, Kandel ER (1999) ERK plays a regulatory role in induction of LTP by theta frequency stimulation and its modulation by beta-adrenergic receptors. Neuron 24:715-726.

Zorrilla EP, Schulteis G, Ormsby A, Klaassen A, Ling N, McCarthy JR, Koob GF, De Souza EB (2002) Urocortin shares the memory modulating effects of corticotropin-releasing factor (CRF): mediation by CRF1 receptors. Brain Res 952:200-210. 